\title{
ANALIZA PRZYCZYNOWOŚCI W DŁUGIM I KRÓTKIM OKRESIE W MODELU POPYTU NA PIENIĄDZ
}

\begin{abstract}
$\mathrm{Z}$ a ry s t r e ś c i. Celem prezentowanego artykułu jest zarysowanie problemu przyczynowości w długim i krótkim okresie, który pozostaje w ścisłym związku z pojęciem przyczyny bezpośredniej i pośredniej, a także zastosowanie procedury testowania przyczynowości zaproponowanej przez Dufour i in. (2003) do zmiennych występujących w kwartalnym modelu popytu na pieniądz dla Polski w latach 1997-2007. Przedstawiony model popytu na pieniądz został zbudowany przy założeniu kointegracji badanych zmiennych. Analiza zależności przyczynowych przeprowadzona na tle modelowanej zależności wskazuje na zgodność modelu empirycznego z teorią ekonomii.

S ło w a k 1 u c z o w e: przyczynowość w sensie Grangera i Hsiao, testowanie przyczynowości w długim i krótkim okresie, model popytu na pieniądz dla Polski.
\end{abstract}

\section{WSTĘP}

Dufour i Renault (1998) zwrócili uwagę na fakt, iż tradycyjne rozumienie definicji przyczynowości w sensie Grangera odnosi się przyczynowości bezpośredniej, ponieważ zmienna zdefiniowana jako przyczyna, posiadająca reprezentację autoregresyjną wywołuje (a ściśle prognozuje) skutek, również posiadający reprezentację autoregresyjną, w następnym okresie. Tak określona przyczyna bezpośrednio styka się $\mathrm{w}$ czasie ze skutkiem, zatem predykcja na kolejne okresy $(h>1)$ może się jedynie odbywać z użyciem prognoz wyznaczonych na okresy poprzednie.

Może się jednak okazać iż będziemy mieć zależność pośrednią, tzn. taką, że nawet jeśli zmienna $X_{t}$ nie ma bezpośredniego wpływu na $Y_{t}$, to może ona być, mimo wszystko, przydatna do prognozowania $Y_{t}$. Wynika to z faktu, iż zmienna $X_{t-1}$ ma wpływ na $Z_{t}$, z kolei $Z_{t}$ implikuje $Y_{t+1}$. Zatem zmienna $X$ wpływa na $Y$, na przykład, na dwa okresy w przód.

Takie rozumienie przyczynowości przy obecności trzeciej zmiennej zaproponował Hsiao (1982). Brak przyczynowości w sensie Hsiao nie zależy od ho- 
ryzontu predykcji, a zależy od współzależności zmiennych występujących w systemie (por. Triacca, 2000). Dufour, Pelletier i Renault (2003), a także Dufour i Tessier (2006) zaproponowali i zastosowali test przyczynowości w sensie Grangera, ale odnoszący się do przyczynowości w tzw. długim okresie, tzn. dla horyzontu predykcji dłuższego niż jeden.

Celem prezentowanego artykułu jest zarysowanie analizowanego problemu, który pozostaje wciąż na uboczu głównego nurtu badawczego w zakresie zależności przyczynowych (por. Osińska, 2008), a ponadto zastosowanie omawianej procedury testowania przyczynowości $\mathrm{w}$ długim i krótkim okresie do zmiennych występujących w kwartalnym modelu popytu na pieniądz dla Polski w latach 1997-2007.

\section{TESTOWANIE PRZYCZYNOWOŚCI W HORYZONCIE H}

Definicja przyczynowości w sensie Grangera jest dobrze znana i powszechna w literaturze ekonometrycznej (por. Granger, 1969; Osińska, 2008). Jako jej rozszerzenie przyjmuje się definicję Hsiao (1982). Można powiedzieć, że zmienna $X_{t}$ nie jest przyczyną $Y_{t}$ w sensie Hsiao przy danym zbiorze informacji $\Omega_{t}=\left\{X_{t}, Y_{t}, Z_{t}\right\}$ wtedy i tylko wtedy, gdy $X_{t}$ i $Z_{t}$ nie są przyczynami $Y_{t}$ w sensie Grangera lub $X_{t}$ nie jest przyczyną $Y_{t}$ i $Z_{t}$ nie jest przyczyną $Y_{t}$. w sensie Grangera. O ile przyczynowość w sensie Grangera implikuje $X_{t} \rightarrow Y_{t+1}$, o tyle przyczynowość w sensie Hsiao pozwala na $X_{t} \rightarrow Y_{t+h}$, co umożliwia analize przyczynowości zarówno bezpośredniej od $X$ do $Y$, jak i pośredniej $X \rightarrow Z \rightarrow Y$, w różnych horyzontach predykcji dla dowolnego $h \geq 1$.

W celu zbadania siły predyktywnej danego związku w długim i krótkim horyzoncie Dufour, Pelletier i Renault (2003) zdefiniowali model VAR w horyzoncie $h$, określającym okres predykcji a nie opóźnień. Zwykły model $\operatorname{VAR}(p)$ stanowi autoregresję o horyzoncie prognozy równym jeden. W notacji zaproponowanej przez Dufour i Renault (1998) jest on dany jako:

$$
W(t)=\mu(t)+\sum_{k=1}^{p} \pi_{k} W(t-k)+\varepsilon(t), t=1, \ldots, T
$$

gdzie: $W(t)=\left(w_{1 t}, w_{2 t}, \ldots, w_{m t}\right)^{\prime}$ jest wektorem o wymiarach $m \times 1, \mu(t)$ jest deterministycznym trendem, zaś proces resztowy jest m-wymiarowym białym szumem. Może on jednak być uogólniony na dowolny horyzont $h$, co daje następującą zależność:

$$
\begin{aligned}
& W(t+h)=\mu^{(h)}(t)+\sum_{k=1}^{p} \pi_{k}^{(h)} W(t+1-k)+\sum_{j=0}^{h-1} \psi_{j} \varepsilon(t+h-j), \\
& t=0, \ldots, T-h
\end{aligned}
$$


przy czym $\psi_{0}=I_{m}$ i $h<T$. Jak łatwo zauważyć, w modelu (2) występuje autokorelacja składnika losowego, stąd jest on generowany przez model średniej ruchomej. Parametry modelu (2) są dane za pomocą następujących formuł:

$$
\begin{aligned}
& \pi_{k}^{(h+1)}=\pi_{k+h}+\sum_{l=1}^{h} \pi_{h-l+1} \pi_{k}^{(l)}=\pi_{k+1}^{(h)}+\pi_{1}^{(h)} \pi_{k}, \quad \pi_{1}^{(0)}=I_{m}, \pi_{k}^{(1)}=\pi_{k}, \\
& \mu^{(h)}(t)=\sum_{k=0}^{h-1} \pi_{1}^{(k)} \mu(t+h-k), \\
& \psi_{h}=\pi_{1}^{(h)} \forall h \geq 0,
\end{aligned}
$$

gdzie elementy macierzy $\psi_{h}$ są współczynnikami odpowiedzi na impuls.

Model (2) można przedstawić w formie macierzowej jako:

$$
w_{h}(k)=\bar{W}_{p}(k) \prod^{(h)}+U_{h}(k) \quad \text { dla } h=1, \ldots H
$$

gdzie: $w_{h}(k)$ i $U_{h}(k)$ są macierzami stopnia $(T-k+1) \times m$ oraz $\bar{W}_{p}(k)$ jest macierzą stopnia $(T-k+1) \times(n+m p)$ :

$$
\begin{aligned}
& w_{h}(k)=\left[\begin{array}{c}
W(0+h)^{\prime} \\
W(1+h)^{\prime} \\
\vdots \\
W(T-k+h)^{\prime}
\end{array}\right]=\left[w_{1}(h, k), \ldots, w_{m}(h, k)\right] ; \bar{W}_{p}(k)=\left[\begin{array}{c}
W_{p}(0)^{\prime} \\
W_{p}(1)^{\prime} \\
\vdots \\
W_{p}(T-k)^{\prime}
\end{array}\right], \\
& W_{p}(t)=\left[\begin{array}{c}
D^{(h)}(t)^{\prime} \\
W(t, p)
\end{array}\right], \Pi^{(h)}=\left[\begin{array}{c}
\gamma(h)^{\prime} \\
\pi^{(h)}
\end{array}\right]=\left[\beta_{1}(h), \beta_{2}(h), \ldots, \beta_{m}(h)\right], \\
& U_{h}(k)=\left[\begin{array}{c}
u^{(h)}(0+h)^{\prime} \\
u^{(h)}(1+h)^{\prime} \\
\vdots \\
u^{(h)}(T-k+h)^{\prime}
\end{array}\right]=\left[u_{1}(h, k), \ldots, u_{m}(h, k)\right], \\
& u_{i}(h, k)=\left[u_{i}(0+h), u_{i}^{(h)}(1+h), \ldots, u_{i}^{(h)}(T-k+h)\right], \\
& u^{(h)}(t+h)^{\prime}=\left[u_{1}^{(h)}(t+h), \ldots, u_{m}^{(h)}(t+h)\right]=\sum_{j=0}^{h-1} \varepsilon(t+h-j)^{\prime} \psi^{\prime}{ }_{j} .
\end{aligned}
$$

Równanie (3) uwzględnia część deterministyczną, postaci:

$$
\mu^{(h)}(t)=\gamma(h) D^{(h)}(t)
$$


gdzie: $\gamma(h)$ jest wektorem parametrów o wymiarach $m \times n$, natomiast $D^{(h)}(t)$ jest wektorem $n \times 1$ zmiennych deterministycznych.

Przyjmując powyższe oznaczenia, brak zależności przyczynowych między zmiennymi można zdefiniować jak następuje. Zakładając, że zasób informacji $\Omega \mathrm{w}$ okresie $t$ spełnia warunki:

$\Omega=\{\Omega(t): t \in T, t>\omega\} \quad$ i $t<t^{\prime} \Rightarrow \Omega(t) \subseteq \Omega\left(t^{\prime}\right) \quad$ dla każdego $t>\omega$ oraz $X=\{X(t): t \in T, t>\omega\}, \quad X(t)=\left(x_{1}(t), \ldots, x_{m_{1}}(t)\right)^{\prime}, \quad x_{i}=(t) \in L^{2}, \quad\left(i=1, \ldots, m_{1}\right)$, a ponadto $Y(t)=\left(y_{1}(t), \ldots, y_{m_{2}}(t)\right)^{\prime}, y_{j}(t) \in L^{2}$ dla $1 \leq j \leq m_{2}$ oraz zakładając, że zbiór $X$ zależy od $\Omega^{l}$, wtedy dla $h \in N$ można przyjąć, że:

1. $X$ nie wywołuje $Y$ w horyzoncie $h$ przy danym $\Omega$, gdy $P[Y(t+h) \mid \Omega(t)]=P[Y(t+h) \mid(\Omega(t)+X(\omega, t))], \quad \forall t>\omega ;$

2. $X$ nie wywołuje $Y$ do horyzontu $h$ przy danym $\Omega$, jeżeli $X$ nie jest przyczyną $Y \mathrm{w}$ sensie Grangera dla każdego $k=1, \ldots, h$

3. X nie wywołuje $\mathrm{Y}$ w żadnym horyzoncie dla danego $\Omega$, jeżeli $X$ nie jest przyczyną $Y$ w sensie Grangera dla każdego $k \in N$.

W celu zbadania braku przyczynowości krótko i długookresowej, Dufour, Pelletier i Renault (2003) proponują prosty test, możliwy do zastosowania w przypadku metod liniowej regresji. Wykorzystując model wektorowej autoregresji $\operatorname{VAR}(p, h)$, którego parametry są oszacowane metodą najmniejszych kwadratów, występowanie przyczynowości można zbadać za pomocą testu typu Walda.

Rozważmy stacjonarny model $\operatorname{VAR}(p, h)$ postaci (3). Jeśli założenia o asymptotycznej normalności najmniejszych kwadratów są spełnione, to dla hipotezy $H_{0}^{(h)}: \pi_{i j k}^{(h)}=0$, gdzie $k=1, \ldots, p$ oraz $\pi_{k}^{(h)}=\left[\pi_{i j k}^{(h)}\right]_{i, j=1, \ldots, m}$ to statystyka:

$$
W\left[H_{o}(h)\right]=T\left[R \hat{\beta}_{i}(h)-r\right]\left[R \hat{V}_{T}\left(\hat{\beta}_{i}\right) R^{\prime}\right]^{-1}\left[R \hat{\beta}_{i}(h)-r\right]
$$

ma rozkład asymptotyczny $\chi^{2}(p)$. Z powyższego wynika, że dla hipotezy $H_{0}^{(h)}$ o braku wpływu $w_{j t}$ na $w_{i t}$, asymptotycznym rozkładem, odpowiadającej statystyki $W\left[H_{0}(h)\right]$ jest $\chi^{2}(p)$. Dlatego też możliwe jest zastosowanie prostego testu Walda w celu zbadania istotności wykorzystania zmiennych w celach prognostycznych.

W przypadku procesów zintegrowanych rzędu 1, odpowiedni model $\operatorname{VAR}(p, h)$ ma postać:

${ }^{1} X(w, t] \subseteq \Omega(t)$ dla każdej liczby całkowitej $t>\omega$, gdzie $X(\omega, t]$ jest przestrzenią Hilberta rozciągniętą na $x_{i}(\tau), i=1, \ldots, m_{1}$ dla $X(\tau), \omega<\tau \leq t$. 


$$
\begin{gathered}
W(t+h)-W(t-p-1)=\mu^{(h)}(t)+\sum_{k=1}^{p} \pi_{k}^{(h)}[W(t+1-k)-W(t-p-1)]+ \\
-B_{p+1}^{(h)} W(t-p-1)+\sum_{j=0}^{h-1} \psi_{j} \varepsilon(t+h-j)
\end{gathered}
$$

gdzie: $B_{p+1}^{(h)}=\left(I_{m}-\sum_{k=1}^{p+1} \pi_{k}^{(h)}\right)$.

Model (6) może być interpretowany jako model korekty błędem w horyzoncie $h$ dla procesów zintegrowanych $\mathrm{w}$ stopniu $1 . \mathrm{Z}$ argumentów przytoczonych w pracy Dufour i in. (2003) wynika, iż oszacowania MNK parametrów $\pi_{k}^{(h)}$ modelu (6) mają rozkład asymptotycznie normalny (por. też Dolado, Lütkepohl, 1996), co pozwala zastosować statystykę Walda postaci (5) do testowania hipotezy $H_{0}^{(h)}$ o braku wpływu $w_{j t}$ na $w_{i t}$. O ile nie nakładamy żadnych restrykcji na parametry $B_{p+1}^{(h)}$, statystyka ta ma nadal rozkład asymptotyczny $\chi^{2}(p)$.

\section{MODELOWANIE POPYTU NA PIENIACDZ}

Tradycja badania popytu na pieniądz w ekonometrii sięga prac Irvinga Fishera, który sformułował podstawy ilościowej teorii pieniądza, rozwiniętej następnie przez Miltona Friedmana. W swej pierwotnej formie, popyt na pieniądz był generowany przez popyt na gotówkę i depozyty bankowe, a jego obieg thumaczyło znane równanie wymiany Fishera. Według teorii Friedmana, istotnym motywem działania człowieka jest bogactwo, rozumiane jako zdyskontowane wszelkie źródła dochodu oraz dóbr konsumpcyjnych. Czynnikami zwiększającymi dochód i prowadzącymi bezpośrednio do zwiększenia bogactwa są: pieniądz, obligacje, akcje, dobra fizyczne i kapitał ludzki. Jako, że $\mathrm{w}$ teorii Friedmana popyt na pieniądz jest rozpatrywany w kontekście popytu na dobra konsumpcyjne i wyprowadzany z realnych funkcji użyteczności, zatem zmiany nominalne nie mogą na niego oddziaływać. Połączenie popytu na pieniądz z kategoriami realnymi powoduje, że model Friedmana jest bardziej stabilny niż teoria Keynesa, który głównie stopie procentowej przypisywał funkcję regulacyjną $\mathrm{w}$ zakresie wielkości popytu na pieniądz. Wobec faktu, że społeczeństwo ma skłonność do utrzymywania większej ilości pieniądza niż tego potrzebuje (motyw spekulacyjny), można bez zbytniej przesady stwierdzić, iż stabilność popytu na pieniądz decyduje o stabilności gospodarki. W gospodarce otwartej, przy nasileniu procesów globalizacyjnych należy przy tym wziąć pod uwagę także popyt na waluty obce, jako alternatywę alokacyjną przy oddziaływaniu motywu spekulacyjnego. 
Standardowe podejście do ekonometrycznego modelowania popytu na pieniądz zakłada badanie kointegracji między procesami uwzględnianymi w analizie (por. np. Ericsson, Sharma, 1998; Kontolemis, 2002; Bruzda, 2006 i wiele innych). Z uwagi na nieobserwowalność popytu na pieniądz jest on aproksymowany za pomocą realnej podaży pieniądza, przy założeniu równowagi na rynku pieniężnym.

Podstawowe równanie popytu na pieniądz można zapisać jako:

$$
(m-p)_{t}=\beta_{1} y_{t}+\beta_{2} R_{t}+\eta_{t}
$$

gdzie:

$m_{t}-$ jest logarytmem nominalnej podaży pieniądza (pieniądz wąski lub szeroki),

$p_{t}-$ jest logarytmem indeksu dóbr i usług konsumpcyjnych,

$y_{t}-$ jest logarytmem wskaźnika realnej aktywności gospodarczej (PKB, wydatki konsumpcyjne)

$R_{t}$ - jest nominalną stopą procentową, interpretowaną jako koszt alternatywny wobec utrzymywania pieniądza.

Należy zwrócić uwagę, iż wymienione zmienne mogą być reprezentowane przez różne kategorie ekonomiczne. W prezentowanym badaniu zostały przyjęte następujące zmienne (w postaci logarytmów):

- $\quad(m 3-p)_{t}-$ szeroki pieniądz,

- $\quad u_{s} d_{t}$ - kurs wymiany PLN/USD;

- $\quad y_{t}-$ kwartalna stopa wzrostu PKB;

- $\quad p_{t}$ - indeks cen dób i usług konsumpcyjnych;

- jako alternatywne przybliżenia $R_{t}$ (roczne stopy procentowe zostały przeliczone na kwartalne):

- $d_{t}$ - przeciętne oprocentowanie depozytów w systemie bankowym,

- $t b_{t}-$ rentowność 52. tygodniowych bonów skarbowych,

- $c a_{t}$ - nominalna stopa procentowa na rachunku bieżącym,

- $(d-c a)_{t}$ - różnica stóp procentowych alternatywnych aktywów: depozytów bankowych i środków na rachunku bieżącym,

- $(t b-c a)_{t}$ - różnica stóp procentowych alternatywnych aktywów: bonów skarbowych i środków na rachunku bieżącym.

Obserwacje kwartalne pochodziły z okresu 1997-2007. Wszystkie zmienne, po odsezonowaniu, okazały się zintegrowane $\mathrm{w}$ stopniu 1 i skointegrowane w stopniu $(1,1)^{2}$. Zastosowanie dwustopniowej procedury Engle'a i Grangera (1987) dało najlepszy wynik w przypadku użycia jako stopy procentowej nominalnego oprocentowania na rachunku bieżącym. Równanie długookresowe ma zatem postać:

\footnotetext{
${ }^{2}$ Wyniki testów ADF, KPSS i Johansena są dostępne u autorki.
} 


$$
m 3-p_{t}=\underset{(3,191)}{-0,084}+\underset{(0,131)}{2,145} y_{t}-\underset{(0,116)}{0,214} c a_{t}-\underset{(0,386))}{2,889} p_{t}+\eta_{t}
$$

$\mathrm{R}^{2}=0,973$; Box-Ljung(4)= 82,503 $(\mathrm{p}=0,0000) ; \operatorname{ADF}(1)=-2,4308(\mathrm{p}=0,0162)$

Wszystkie parametry w równaniu długookresowym są statystycznie istotne i co ważne posiadają właściwe znaki, co umożliwia jego interpretację jako długookresowej ścieżki równowagi systemu monetarnego w Polsce w badanym okresie, obejmującej $\mathrm{z}$ jednej strony sferę realną reprezentowaną przez PKB, $\mathrm{z}$ drugiej natomiast sferę monetarną, reprezentowaną przez stopę procentową oraz wskaźnik cen. Należy zwrócić uwagę, iż okres objęty analizą można traktować jako względnie jednorodny, praktycznie po zakończeniu procesów transformacji, rozpoczętych w roku 1989. Słabym punktem całej analizy wydaje się fakt, że szeregi czasowe przyjęte do badania były dość krótkie (44 obserwacje), co wynikało z dostępności danych dotyczących PKB.

Równanie dostosowawcze (ECM) ma postać:

$$
\Delta(m 3-p)_{t}=\underset{(0,002)}{0,031+\underset{(0,045)}{0,188} \Delta u s d_{t}}-\underset{(0,001)}{0,032} \Delta c a_{t}-\underset{(0,194))}{1,405} \Delta p_{t}-\underset{(0,020)}{0,150 e m_{t-1}}+\varepsilon_{t}
$$

$\mathrm{R}^{2}=0,796$; Box-Ljung $(4)=1,901(\mathrm{p}=0,7540) \mathrm{DF}=-6,4301(\mathrm{p}=0,0000)$

Należy zwrócić uwagę, iż PKB występuje tylko w równaniu długookresowym, podczas, gdy krótkookresowe dostosowania do sytuacji na rynku opierają się na zmiennych stricte monetarnych. Na krótkookresowe zmiany popytu na pieniądz wpływa najsilniej zmiana wskaźnika cen dóbr i usług konsumpcyjnych, a następnie zmiana kursu walutowego i zmiana stopy procentowej na rachunku bieżącym. Wzrost wskaźnika cen dóbr i usług konsumpcyjnych o 1 punkt procentowy $\mathrm{w}$ danym kwartale powoduje spadek popytu na pieniądz o 1,4 w tym samych okresie. Podobne, choć słabsze oddziaływanie posiada zmiana oprocentowania rachunków bieżących, podczas gdy deprecjacja polskiej waluty względem dolara wywołuje wzrost popytu na pieniądz krajowy. Szybkość dostosowania wynosi 15\% kwartalnie, co oznacza, że dostosowanie popytu na pieniądz do poziomu równowagi długookresowej zajmuje około 5 kwartałów.

\section{TESTOWANIE PRZYCZYNOWOŚCI W MODELU POPYTU NA PIENIA¿DZ}

Testowanie przyczynowości w sensie Grangera, rozszerzonym przez Hsiao ma sens w przypadku równania krótkookresowego, jako że równanie długookresowe reprezentujące ścieżkę równowagi badanych zmiennych jest interpretowane jako steady state, niezależnie od czasu. W prezentowanym badaniu wykorzystano wszystkie alternatywne zmienne reprezentujące kategorie występujące $\mathrm{w}$ modelu popytu na pieniądz, w celu weryfikacji oszacowanej wcześniej specyfikacji modelowej. Ze względu na kwartalny charakter obserwacji, przyjęto, iż model $\operatorname{VAR}(p, h)$, będący podstawą testowania uwzględniał 4 opóźnienia 
$(p=4)$ a horyzont prognozy $h$ sięgał 8 okresów w przód. Z uwagi na to, że rozpatrywane szeregi były zintegrowane $\mathrm{w}$ stopniu 1 , do testowania wykorzystano model postaci (6). Do oszacowania macierzy wariancji-kowariancji wykorzystano procedurę Neweya i Westa (1987). Wyniki testowania w postaci wartości $p$ dla statystyki Walda, przy założeniu asymptotycznego rozkładu $\chi^{2}(p)$ zostały przedstawione w tabeli $1^{3}$.

Tabela 1. Wyniki testowania przyczynowości w modelu popytu na pieniądz w długim i krótkim okresie

\begin{tabular}{|c|c|c|c|c|c|}
\hline Zmienna & $\Delta(m 3-p) t$ & $\Delta(m 3-p) t+1$ & $\Delta(\mathrm{m} 3-\mathrm{p}) \mathrm{t}+2$ & $\Delta(m 3-p) t+3$ & $\Delta(m 3-p) t+4$ \\
\hline$\Delta$ tbt-k & 0,5584 & 0,0224 & 0,1961 & 0,0008 & 0,7835 \\
\hline$\Delta$ (tb-ca)t-k & 0,0242 & 0,0727 & 0,6679 & 0,5786 & 0,6512 \\
\hline$\Delta(\mathrm{d}-\mathrm{ca}) \mathrm{t}-\mathrm{k}$ & 0,5275 & 0,9378 & 0,6382 & 0,9707 & 0,8921 \\
\hline$\Delta$ cat-k & 0,4457 & 0,2336 & 0,9106 & 0,0097 & 0,4116 \\
\hline$\Delta \mathrm{dt}-\mathrm{k}$ & 0,6389 & 0,9303 & 0,8364 & 0,8568 & 0,9168 \\
\hline$\Delta \mathrm{pt}-\mathrm{k}$ & 0,0036 & 0,0012 & 0,0206 & 0,2732 & 0,9384 \\
\hline$\Delta$ usdt-k & 0,0063 & 0,0102 & 0,0288 & 0,0075 & 0,1442 \\
\hline$\Delta \mathrm{yt}-\mathrm{k}$ & 0,0004 & 0,2891 & 0,7564 & 0,9036 & 0,9566 \\
\hline Zmienna & & $\Delta(m 3-p) t+5$ & $\Delta(m 3-p) t+6$ & $\Delta(m 3-p) t+7$ & $\Delta(\mathrm{m} 3-\mathrm{p}) \mathrm{t}+8$ \\
\hline$\Delta$ tbt-k & & 0,3462 & 0,0151 & 0,1389 & 0,3058 \\
\hline$\Delta$ (tb-ca)t-k & & 0,4633 & 0,1832 & 0,0742 & 0,0002 \\
\hline$\Delta(\mathrm{d}-\mathrm{ca}) \mathrm{t}-\mathrm{k}$ & & 0,9463 & 0,5871 & 0,0805 & 0,2173 \\
\hline$\Delta$ cat-k & & 0,0637 & 0,1035 & 0,2401 & 0,6169 \\
\hline$\Delta \mathrm{dt}-\mathrm{k}$ & & 0,7556 & 0,2551 & 0,1974 & 0,2593 \\
\hline$\Delta \mathrm{pt}-\mathrm{k}$ & & 0,9498 & 0,3948 & 0,5859 & 0,7504 \\
\hline$\Delta$ usdt-k & & 0,5023 & 0,6416 & 0,9828 & 0,7421 \\
\hline$\Delta y t-k$ & & 0,7793 & 0,4304 & 0,8876 & 0,9542 \\
\hline
\end{tabular}

W tabeli podane zostały wartości $p$ statystyki Walda dla procesów stacjonarnych. Wartości $p<0,05$ wskazujące na odrzucenie hipotezy o braku przyczynowości w horyzoncie $h$ zostały zaznaczone pogrubioną czcionką. Ponadto przyjęto $k=\{1, \ldots, 4\}$.

Źródło: opracowanie własne.

Analiza rezultatów zaprezentowanych w tabeli 1 wskazuje na fakt, iż większość zmiennych występujących w kwartalnym modelu popytu na pieniądz ma charakter przyczyn bezpośrednich. Należą do nich przede wszystkim $p_{t}, u s d_{t}$ i $y_{t}$. Czas oddziaływania tych przyczyn na zmiany popytu na pieniądz jest różny, od jednego okresu (jak w przyczynowości w sensie Grangera) dla $y_{t}$ do trzech lub czterech okresów w przód dla wskaźnika cen $p_{t}$ i kursu walutowego

\footnotetext{
${ }^{3}$ Dufour i in. (2003) wskazują na słabe własności statystyki Walda dla rozkładu asymptotycznego, proponując wyznaczenie wartości krytycznych na podstawie procedury bootstrap. Jednak w rozpatrywanym modelu większość zmiennych ma charakter przyczyn bezpośrednich, stąd zastosowanie wartości $p$ rozkładu asymptotycznego jest po części uzasadnione.
} 
$u s d_{t}$, odpowiednio. Wiadomo, że wzrost kursu walutowego ma poprzez wskaźnik cen importu wpływ na wzrost wskaźnika cen dóbr i usług produkcyjnych, dlatego te powiązania rozkładają się w czasie, tworząc zależność, przedstawioną na wykresie 1 .

Spośród badanych aproksymant stóp procentowych, największą siłę prognostyczną posiadały: rentowość bonów skarbowych 52 . tygodniowych $t b_{t}$, różnica między rentownością bonów skarbowych a oprocentowaniem na rachunku bieżącym $(t b-c a)_{t}$, która okazała się przyczyną bezpośrednią, jak również oprocentowanie rachunków bieżących $c a_{t}$. Z kolei średnie oprocentowanie depozytów bankowych $d_{t}$ oraz różnica stóp procentowych $(d-c a)_{t}$ w ogóle nie miały wpływu na popyt na pieniądz w Polsce w latach 1997-2007.

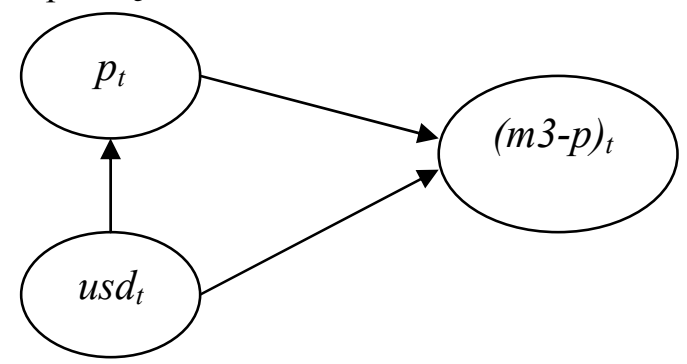

Wykres 1. Bezpośrednie i pośrednie zależności między wskaźnikiem cen, kursem walutowym i popytem na pieniądz w Polsce

Źródło: opracowanie własne.

Wynika z tego, iż polityka pieniężna banku centralnego w postaci kolejnych emisji bonów skarbowych w znaczącym stopniu regulowała popyt na pieniądz w kraju, na który ponadto wpływ miały zmiany ogólnego poziomu oprocentowania na rachunkach bieżących, jak również nieuwzględniony tutaj znaczny udział inwestycji na rynku kapitałowym, zwłaszcza w postaci funduszy inwestycyjnych.

\section{ZAKOŃCZENIE}

W artykule omówiona została procedura analizy zależności przyczynowych w długim i krótkim okresie. W tym celu wykorzystano definicję przyczynowości Hsiao, uogólniająca pojęcie przyczynowości w sensie Grangera w przypad$\mathrm{ku}$ obecności więcej niż dwóch zmiennych. Ponadto omówiona została i zastosowana także koncepcja testowania przyczynowości w długim i krótkim okresie zaproponowana przez Dufour, Pelletier i Renault (2003). Zastosowanie testu przyczynowości $\mathrm{w}$ długim i krótkim okresie do modelu popytu na pieniądz w Polsce wskazało na występowanie zależności bezpośrednich między wskaźnikiem cen, kursem walutowym oraz PKB, jak również na zróżnicowany okres wpływu zmiennych reprezentujących stopę procentową. Najlepszymi aproksymantami stopy procentowej okazały się: rentowność bonów skarbowych 52- 
tygodniowych, oprocentowanie środków zdeponowanych na rachunkach bieżących, jak również różnica wymienionych tu stóp procentowych.

Przedstawiona procedura może być wykorzystywana do ustalania odstępu czasowego między przyczyną a skutkiem i, tym samym, pomocna w określeniu przyczyn bezpośrednich i pośrednich w łańcuchu zależności przyczynowych.

\title{
Literatura
}

Bruzda J. (2006), Empirical Verification of Money Demand Models: Non-linear Cointegration Analysis, [w:] Zieliński Z. (red.) Dynamic econometric models, UMK, Toruń, 113-123.

Dolado J. J., Lütkepohl H. (1996), Making Wald Test Work for Cointegrated VAR Systems, „Econometric Reviews", 15, 369-386.

Dufour J.-M., Pelletier D., Renault E.(2003), Short-Run and Long-run Causality in Time Series: Interference; Universite de Montreal, working paper.

Dufour J.-M., Renault E. (1998), Short Run and Long Run Causality in Time Series: Theory, „Econometrica”, 66, 1099-1112.

Dufour J.-M., Tessier D. (2006), Short-Run and Long-Run Causality between Monetary Policy Variables and Stock Prices, Bank of Canada, working paper.

Engle R. F., Granger C. W. J. (1987), Cointegration and Error Correction: Representation, Estimation and Testing, „Econometrica”, 55, 251-276.

Ericsson N. R., Sharma S. (1998), Broad Money Demand and Financial Liberalization in Greece, „Empirical Economics”, 23, 417-436.

Granger C. W. J. (1969), Investigating Causal Relations by Econometric Models and CrossSpectral Methods, „Econometrica”, 37, 422-459.

Hsiao C. (1982), Autoregressive Modeling and Causal Ordering of Economic Variables, „Journal of Economic Dynamic and Control", 4, 243-259.

Kontolemis, Z. G. (2002), Money Demand in the Euro Area: Where Do We Stand (Today)?, IMF Working Paper 02/185, 1-30.

Newey W. K., West K. D. (1987), A Simple, Positive Semi-Definite, Heteroskedasticity and Autocorrelation Consistent Covariance Matrix, „Econometrica”, 55, 703-708.

Osińska M. (2008), Ekonometryczna analiza zależności przyczynowych, Wyd. Naukowe UMK, Toruń 2008.

Triacca U. (2000), On the Hsiao Definition of Non-causality, „Economics Letters”, 66, 261-264.

\section{LONG AND SHORT RUN CAUSALITY ANALYSIS IN THE MONEY DEMAND MODEL FOR POLAND}

\begin{abstract}
A b s tract. The purpose of the article is to analyse the Granger causality problem in the long as well as short run. The straightforward relation of the mentioned concept with direct and indirect cause ideas has beaen emphasized. The testing procedure proposed in Dufour et al. (2003) was used to search for causality in the long and short run in the quarterly model of demand for money in Poland in 1997-2007. The model was constructed on the basis of cointegration concept. Causality analysis shows that the empirical model remains in agreement with economic theory.
\end{abstract}

K e y w o r d s: Granger and Hsiao concepts of causality, testing for causality in the long and short run, money demand model for Poland. 